\title{
The Influence of the Dietary Cu-Glycine Complex on the Histomorphology of Cancellous Bone, Articular Cartilage, and Growth Plate as well as Bone Mechanical and Geometric Parameters Is Dose Dependent
}

\author{
Ewa Tomaszewska ${ }^{1} \cdot$ Piotr Dobrowolski $^{2}$ - Malgorzata Kwiecień ${ }^{3}$ • \\ Anna Winiarska-Mieczan ${ }^{3}$ - Agnieszka Tomczyk ${ }^{1} \cdot$ Siemowit Muszyński $^{4}$
}

Received: 27 September 2016 / Accepted: 7 November 2016/Published online: 26 November 2016

(C) The Author(s) 2016. This article is published with open access at Springerlink.com

\begin{abstract}
Copper $(\mathrm{Cu})$ is required for all basic biochemical and physiological processes. The objective of this study was to compare the effect of two different chemical forms (sulfates and glycinate chelates also below the recommended dose) of $\mathrm{Cu}$ administered to adult rats on the biomechanical and morphometric properties of femur. Male rats at the age of 12 weeks were used in the 12-week experiment. The control diet provided the required $\mathrm{Cu}$ level from sulfate $(\mathrm{S}-\mathrm{Cu})$, and the other diets were supplemented with $\mathrm{Cu}$-glycine complex. The $\mathrm{Cu}$ Gly-treatment, irrespective of its concentration, did not influence the bone mass and length. The Cu-Gly-treatment in 100 and $75 \%$ of daily demand increased mechanical endurance. The Cu-Gly-treatment (regardless of its concentration) increased the real bone volume in epiphysis and decreased the total thickness and zone I of the articular cartilage compared to the control group supplemented with $\mathrm{S}-\mathrm{Cu}$. The $\mathrm{Cu}-\mathrm{Gly}-$ treatment enhanced the content of proteoglycans (except the OG50 group). Dietary $\mathrm{Cu}$ given to adult rats in the $\mathrm{Cu}-\mathrm{Gly}$ complex covering the daily demand in $75 \%$ exerted a positive
\end{abstract}

Ewa Tomaszewska ewaRST@interia.pl

1 Department of Animal Physiology, Faculty of Veterinary Medicine, University of Life Sciences in Lublin, Akademicka 12, 20-950 Lublin, Poland

2 Department of Comparative Anatomy and Anthropology, Maria Curie-Skłodowska University, Akademicka 19, 20-033 Lublin, Poland

3 Institute of Animal Nutrition and Bromatology, University of Life Sciences in Lublin, Akademicka 13, 20-950 Lublin, Poland

4 Department of Physics, Faculty of Production Engineering, University of Life Sciences in Lublin, Akademicka 13, 20-950 Lublin, Poland effect on bone metabolism and appeared to be the most effective among the investigated doses of the organic form.

Keywords Copper · Cu-Gly · Bone histomorphometry · Mechanical parameter $\cdot$ Adult rat

\section{Introduction}

Copper $(\mathrm{Cu})$ is the third most abundant essential trace element in the body of animals and humans, besides iron and zinc. The liver and other organs contain the highest amounts of $\mathrm{Cu}$ among all the tissues, in contrast to the lowest content in bones. The amount of $\mathrm{Cu}$ in the body alters during the lifetime in living organisms [1,2]. A comparative study in long-living mammals demonstrates that $\mathrm{Cu}$ concentrations in cartilage with adjacent compact bone is the highest in foxes and the lowest in humans, while in spongy bone they are the highest in dogs and the lowest in foxes [3]. It is important that $\mathrm{Cu}$ plays important functional roles in bone metabolism and turnover. It is known to be essential for normal growth and development of the skeleton in humans and in animals [4]. As an essential cofactor, $\mathrm{Cu}$ is needed for the action of various enzymes, including lysyl oxidase, i.e., a Cu-dependent enzyme that acts only on extracellular collagen molecules regulating their total enzymatic cross-link formation in connective tissue. The enzyme mediates the final step in the biosynthesis of, first of all, collagen as well as elastin and keratin (hair keratinization) and normalizes the deposition of calcium and phosphorus in the bones [5]. Studies on $\mathrm{Cu}$ supplementation in humans and animals indicate that a deficiency of $\mathrm{Cu}$ leads to bone loss and reduced bone mass, resulting in a decrease in its mechanical strength and subsequent fractures [6]. The possible underlying causes of these changes are functional defects of osteoblasts 
(bone tissue-forming cells), while the activity of osteoclasts (bone tissue removing cells) remains unchanged [4]. The process of bone formation requires an adequate and constant supply of nutrients, including $\mathrm{Cu}$ [7]. Since bones undergo continuous remodeling, an inadequate supply of $\mathrm{Cu}$ could not support the formation phase of bone remodeling and this could lead to the clinical risk of osteoporosis in later life, resulting in problems with locomotor function. Moreover, in humans, copper supplementation for 2 years was associated with reduction in bone loss in perimenopausal and postmenopausal women [7]. Thus, the role of $\mathrm{Cu}$ in the metabolism of connective tissue is so prominent that one can speculate that inadequate $\mathrm{Cu}$ dietary intake could be an important factor in the etiology of bone loss or osteoporosis and even osteoarthritis in adults.

Copper is one of the microelements used in combination with amino acids. Feed grade chelates based on glycine seem to be a good solution to supplement microelement deficiency in feed rations. Glycine, as a chelate component, is the most easily assimilable amino acid, which, with its wide range of applications, additionally improves the values of this additive [8].

The objective of this study was to compare the effect of two different chemical forms (sulfates and glycinate chelates) of $\mathrm{Cu}$ administered in feed mixtures to adult rats on the biomechanical and morphometric properties of femur. The next aim was to evaluate the effects of the diet containing two levels of $\mathrm{Cu}$ in the $\mathrm{Cu}$-glycine complex, below the recommended dose ( 75 and $50 \%$ of daily demand), on bone metabolism and cartilage morphology in adult rats. The present study was also performed to test the hypothesis that $\mathrm{Cu}$ long-term treatment in a lowered amount in relation to the daily demand could not negatively influence the metabolism of the skeletal system of adults. For this purpose, the present study involved a combined use of multiple methods, i.e., mechanical endurance and light microscopy in combination with a histochemical method to characterize the role of $\mathrm{Cu}$ in adult nutrition.

\section{Materials and Methods}

The experimental procedures used throughout this study were approved by the Local Ethics Committee on Animal Experimentation of University of Life Sciences of Lublin, Poland. The rats were maintained in an animal house according to the guidelines of this committee. All efforts were made to minimize the number of animals used as well as their suffering.

\section{Animals, Breeding, and Experimental Design}

Male adult Wistar rats $(n=48)$ at the age of 12 weeks at the start of the experiment were used in the experiment lasting 12 weeks (excluding the acclimatization in the first week).
Clinically healthy rats were individually kept in Macrolon cages at $21 \pm 1{ }^{\circ} \mathrm{C}$ and $55 \%$ humidity and 12-h light and dark cycles. The rats were randomly divided into the control and three experimental groups (each $n=12$ ), depending on the different levels of organic $\mathrm{Cu}$ supplementation. All the animals had free access to distilled water (no $\mathrm{Cu}$ ) and were fed ad libitum. The composition of basal diet comprised crude protein $\min .14 .5 \%$, crude fat $\min .1 .5 \%$, crude fiber $\min .5 \%$, and ash $10 \%$. The content of vitamin and mineral premixes of the diet is presented in Table 1. The control group was fed a standard diet (LSM, Agropol S.J., Motycz, Poland), which provided the required $\mathrm{Cu}$ level for rats in an inorganic form (the IN group; $5 \mathrm{mg} / \mathrm{kg}$ of body weight per day from sulfate (S-Cu; $\mathrm{CuSO}_{4}$; Avantor Performance Materials Poland S.A., Lublin, Poland)) [9]. In turn, the other animals (the OG100 group) were fed the same standard diet, which provided the required $\mathrm{Cu}$ level for rats in an organic form as a $\mathrm{Cu}$ amino acid chelate $(5 \mathrm{mg} / \mathrm{kg}$ of body weight per day from the $\mathrm{Cu}-$ glycine complex; Cu-Gly; ARKOP Sp. z o.o., Bukowno, Poland). The rats from the OG75 group received standard diet, which provided a lowered $\mathrm{Cu}$ level in an organic form covering $75 \%$ of daily demand $(3.75 \mathrm{mg} / \mathrm{kg}$ of body weight per day). The rats from the OG50 group received standard diet, which provided a lowered $\mathrm{Cu}$ level in an organic form covering $50 \%$ of daily demand $(2.5 \mathrm{mg} / \mathrm{kg}$ of body weight per day). Water and feed consumption was measured weekly. At the end of the experiment, the rats were fasted for $24 \mathrm{~h}$ and euthanized one by one with carbon dioxide inhalation and by dislocation of the spine.

\section{Plasma Biochemical Analyses}

Blood samples were collected (two times, after 6 weeks of the duration of the study and at the end) carefully for blood plasma biochemical analysis using standard venipuncture of the

Table 1 The composition of vitamin and mineral premixes of the diet (per kilogram dry matter) fed to rats during the study

\begin{tabular}{ll}
\hline Components & Per $1 \mathrm{~kg}$ of premix \\
\hline Manganese (mg) & 5000 \\
Iron (mg) & 5000 \\
Zinc (mg) & 2500 \\
Iodine (mg) & 75 \\
Pantothenic acid (D-calcium pantothenate) (mg) & 900 \\
Retinol acetate (UI) & 800,000 \\
Cholecalciferol (UI) & 100,000 \\
Tocopherol (mg) & 4964 \\
Menadione sodium bisulphite (mg) & 300 \\
Riboflavin (mg) & 600 \\
Pyridoxine HCL (mg) & 60 \\
Cyanocobalamin (mg) & 1.2 \\
\hline
\end{tabular}


heart. The plasma was immediately separated by centrifugation and stored at $-25{ }^{\circ} \mathrm{C}$ for further analysis. The plasma concentration of $\mathrm{Cu}, \mathrm{Fe}$, and $\mathrm{Zn}$ was determined by the colorimetric method using a Metrolab 2300 GL unit (Metrolab SA, Buenos Aires, Argentina) and ready-made sets produced by the company BioMaxima (Lublin, Poland).

\section{Bone Collection and Analysis}

The bone length and weight were measured after removal of soft tissues from the left femora. Each bone was wrapped in gauze soaked in isotonic saline and stored at $-25{ }^{\circ} \mathrm{C}$ for further analysis.

Geometric properties such as the cross-section area (A), mean relative wall thickness (MRWT), and cortical index (CI) were estimated on the basis of horizontal and vertical diameter measurements of the mid-diaphyseal cross section of bone using a method described previously $[10,11]$.

The mechanical properties of the femur were determined for the bones after 3 -h thawing at room temperature using the three-point bending test. The mechanical properties were examined on a Zwick Z010 universal testing machine (Zwick GmbH \& Company KG, Ulm, Germany) equipped with a measuring head (Zwick GmbH \& Company KG, Ulm, Germany) with an operation range up to $10 \mathrm{kN}$, linked to a computer with TestXpert II 3.1 software (Zwick GmbH \& Company KG, Ulm, Germany) registering the relationship between force perpendicular to the longitudinal axis of the bone and the resulting displacement. The distance between the supports was set at $40 \%$ of the total bone length. The measuring head loaded bone samples at a constant speed of $10 \mathrm{~mm} / \mathrm{min}$ [12]. The ultimate strength was determined as a point at which disintegration of tissue occurred [10].

After removal of soft tissues, the joint with no visible lesions and degenerative changes was opened and full-thickness cartilage was excised with bone specimens. Cylindrical 20-mm thick samples (cartilage and bone) were taken from the same anatomical position in the rats' knee joint, i.e., from the middle of the lateral femoral condyle (containing epiphysis and metaphysis) immediately after euthanasia. Sagittal sections of the cartilage and bone were cut perpendicular to the articular surface [13]. The tissue samples were subjected to typical common histology and microscopy procedures [14]. Fourmicrometer thick sections were cut. Goldner's trichrome staining was used to assess the morphology of the growth plate cartilage and the articular cartilage [14, 15]. Additionally, articular cartilage proteoglycans were stained with Safranine O (SO) [11]. Microscopic bright-field images were collected using a confocal microscope Axiovert 200M (Carl Zeiss, Jena, Germany) equipped with a camera AxioCam HRc (Carl Zeiss, Jena, Germany) and a halogen lamp [11].

The analysis of the collected images was performed with the use of graphical analysis software Olympus cellSens version 1.5 (Olympus, Tokyo, Japan). The thickness of the following zones reserve (I; cells exist singly or in pairs separated by an abundant extracellular matrix), proliferation (II; chondrocytes assume a flattened shape and are arranged in longitudinal columns; they enlarge and divide), hypertrophy (III; the cell size abruptly increases and the columnar arrangement is less regular), and ossification (IV; the region where the transition from cartilage to bone occurs with degeneration and death of chondrocytes) was measured at four sites along the growth plate cartilage and an average was calculated $[13,16]$. Similarly, the thickness of the main zones of the articular cartilage, i.e., horizontal (superficial surface I; chondrocytes are small and flattened parallel to the surface), transitional (II; chondrocytes are large and round, occur singly or in isogenous groups), radial (III; spherical chondrocytes lie in columns), and calcified zone (IV; a zone that rests directly on the subchondral bone) was measured [17].

The bone volume (BV) and tissue volume (TV) were measured in the photographs of the bone tissue sections using the pixel count, and the relative bone volume (BV/TV\%) was assessed. Other parameters examined for trabecular bone (epiphysis and metaphysis) included trabecular thickness (Tb.Th) and trabecular separation ( $\mathrm{Tb} . \mathrm{Sp})$ defined as the distance between the edges of adjacent trabeculae (measured directly) [12, 14].

After evaluating the strength and structural properties, the bones were defatted, dried to constant mass, and finally mineralized in a muffle furnace at $600{ }^{\circ} \mathrm{C}$ [18]. The content of $\mathrm{Cu}$ in the bones was determined by atomic absorption spectrometry using a Unicam 939/959 apparatus. The content of $\mathrm{Cu}$ in the bone was calculated as the content of these components in crude ash.

\section{Statistical Analysis}

All the results are expressed as means $\pm \mathrm{SD}$ (standard deviation). Differences between the means were tested with the oneway ANOVA and post hoc Tukey's test as the correction for multiple comparisons. Normal distribution of data was examined using the W. Shapiro-Wilk test and equality of variance was tested by the Brown-Forsythe test. A $P$ value of less than 0.05 was considered statistically significant. All statistical analyses were carried out by means of Statistica 12 software (StatSoft, Inc., Tulsa, OK, USA; http://www.statsoft.com).

\section{Results}

\section{Body Mass, Feed and Water Consumption}

The initial values of body mass of the control rats and animals treated with the organic $\mathrm{Cu}$ form (regardless of the amount of daily demand) were similar. After 6 weeks of the treatment, the rats supplemented with the organic form of $\mathrm{Cu}$, 
irrespective of its amount, weighed more than the animals from the control group administered with the inorganic form. At the end of study, after 12 weeks of the treatment, only rats from the OG75 group were heavier, compared to the other groups (Table 2). Weekly water and feed consumption did not differ among all the groups, irrespective of the form of the supplemented $\mathrm{Cu}$ and its concentration.

\section{$\mathrm{Cu}, \mathrm{Fe}$, and $\mathrm{Zn}$ Content in Blood Plasma}

The $\mathrm{Cu}$ plasma concentration of the rats treated with the organic form of $\mathrm{Cu}$ (irrespective of its concentration) was significantly higher than in the control rats administered with $\mathrm{S}-\mathrm{Cu}$ (Fig. 1A). The Fe (Fig. 1B) and Zn (Fig. 1C) plasma concentrations were similar in the control rats and animals supplemented with the organic form of $\mathrm{Cu}$ (regardless of the amount of daily demand) and did not differ between each other (Fig. 1).

\section{Bone Cu Content}

The bone $\mathrm{Cu}$ content in the rats supplemented with the recommended $\mathrm{Cu}$ dose, irrespective of its form, was higher than the content exhibited by the other Cu-Gly-treated groups (Fig. 2).

\section{Bone Morphology, Geometry, and Mechanical Properties}

The intake of $\mathrm{Cu}$ in the $\mathrm{Cu}-\mathrm{Gly}$ form, irrespective of its concentration, did not influence the bone mass and length or the mass/length ratio (Table 3). However, Cu-Gly administration in $100 \%$ of daily demand decreased all measured diameters; in $75 \%$, it decreased the horizontal internal diameter (h), and in $50 \%$, it decreased both internal diameters $(\mathrm{h}, \mathrm{b})$, compared to the control group ( $\mathrm{S}-\mathrm{Cu})$. Moreover, $\mathrm{Cu}$-Gly influenced the horizontal internal diameter, irrespective of its concentration, while its effect on the other diameters was dependent on the concentration (Table 3). Further, Cu-Gly increased the cortical index, irrespective of its concentration. An increase in the cross-section area was observed in the OG50 group, and higher MRWT was found in the OG100 and OG50 groups. On the other hand, a decrease in the values of the moment of inertia was noted in the OG100 group, and a lower index of gyration was calculated in the OG100 and OG50 groups, compared to the other groups (Table 3).

The Cu-Gly-treatment in 100 and $75 \%$ of daily demand resulted in an increase in all mechanical parameters (Table 3).

\section{Bone Histomorphometry}

Microscopic assessment of cancellous bone in rats supplemented with the organic form of $\mathrm{Cu}$ (regardless of the amount of daily demand) showed a significant increase in the real bone volume in the epiphysis, compared to the control supplemented with $\mathrm{S}-\mathrm{Cu}$ (Table 4). Moreover, the Cu-Gly supplementation in the OG50 group resulted in an increase in the mean trabecular thickness in the epiphysis, compared to the other groups. Additionally, a decrease in the mean and maximal trabecular space in the OG100 and OG50 groups and in the mean maximal trabecular space in the OG75 group was noted, compared to the S-Cu-treated group (Table 4).

Further, a decrease in the real bone volume in the metaphysis linked with a decrease in the mean trabecular thickness was observed in the OG100 group, compared to the control group ( $\mathrm{S}-\mathrm{Cu}$ ). Additionally, the highest increase in the trabecular space was observed in this group, compared to the other groups (Table 4). Moreover, the $\mathrm{Cu}$-Gly-treatment in $50 \%$ of daily demand resulted in a decrease in the bone volume connected with decreased trabecular thickness and increased space in the metaphysis, compared to the control group (Table 4). However, no decrease in the real bone volume was observed in the OG75 group, but a decrease in the thickness of trabeculae was noted in this group, compared to the control group (S-Cu) (Table 4).
Table 2 Mean weekly water and daily feed consumption, the body weight (initial, after 6 weeks, and 12 weeks as final body weight) in control rats and treated with different levels of Cu-Gly

\begin{tabular}{lllllll}
\hline Group & $n$ & \multicolumn{2}{l}{ Body weight, g } & $\begin{array}{l}\text { Water } \\
\text { consumption (ml) }\end{array}$ & $\begin{array}{l}\text { Feed } \\
\text { consumption (g) }\end{array}$ \\
\cline { 3 - 5 } & & $\begin{array}{l}\text { Initial body } \\
\text { weight }(\mathrm{g})\end{array}$ & After 6 weeks & After 12 weeks & & \\
\hline CONT & 12 & $356.8 \pm 28.4$ & $396.2^{\mathrm{b}} \pm 26.9$ & $464.2^{\mathrm{a}} \pm 39.8$ & $85.3 \pm 14.8$ & $163.9 \pm 13.8$ \\
OG100 & 12 & $352.4 \pm 24.9$ & $453.3^{\mathrm{a}} \pm 21.1$ & $476.9^{\mathrm{a}, \mathrm{b}} \pm 30.6$ & $83.5 \pm 12.6$ & $165.6 \pm 17.3$ \\
OG75 & 12 & $357.2 \pm 12.9$ & $467.4^{\mathrm{a}} \pm 19.9$ & $499.8^{\mathrm{b}} \pm 6.0$ & $84.7 \pm 16.2$ & $167.1 \pm 17.3$ \\
OG50 & 12 & $356.9 \pm 10.8$ & $453.2^{\mathrm{a}} \pm 22.0$ & $488.6^{\mathrm{a}, \mathrm{b}} \pm 15.3$ & $85.8 \pm 12.3$ & $166.2 \pm 13.5$ \\
SEM & 2.883 & 9.601 & 10.033 & 2.120 & 1.884 \\
$P$ value & 0.930 & 0.001 & 0.031 & 0.855 & 0.996 \\
\hline
\end{tabular}

Data given are mean $\pm \mathrm{SD}$. CONT - the control group received $\mathrm{Cu}$ in $100 \%$ of daily demand from sulfate $(\mathrm{S}-\mathrm{Cu})$, OG100 - the group received $\mathrm{Cu}$ in $100 \%$ of daily demand from $\mathrm{Cu}-\mathrm{Gly}$, OG75 - the group received $\mathrm{Cu}$ in $75 \%$ of daily demand from $\mathrm{Cu}-\mathrm{Gly}$, OG50 - the group received $\mathrm{Cu}$ in $50 \%$ of daily demand from $\mathrm{Cu}-\mathrm{Gly}$

${ }^{\mathrm{a}, \mathrm{b}, \mathrm{c}}$ Mean values in rows with different letters differ significantly at $P<0.05$ 
Fig. 1 The plasma concentration of copper $(\mathrm{Cu})(\mathbf{a})$, iron $(\mathrm{Fe})(\mathbf{b})$, and zinc $(\mathrm{Zn})(\mathbf{c})$ in blood plasma of 24-week-old rats treated with $\mathrm{Cu}$ in organic (Cu-Gly) and inorganic form $(\mathrm{S}-\mathrm{Cu})$ after 6 and 12 weeks of the duration of the study. Data given are mean $\pm \mathrm{SD}$, $* P<0.05$. CONT - the control group received $\mathrm{Cu}$ in $100 \%$ of daily demand from sulfate. OG100 - the group received $\mathrm{Cu}$ in $100 \%$ of daily demand from $\mathrm{Cu}-\mathrm{Gly}$. OG75 - the group received $\mathrm{Cu}$ in $75 \%$ of daily demand from Cu-Gly. OG50 the group received $\mathrm{Cu}$ in $50 \%$ of daily demand from $\mathrm{Cu}-\mathrm{Gly}$. Differences between letters given above columns $(\mathbf{a}, \mathbf{b})$ mean significant differences with $P<0.05$
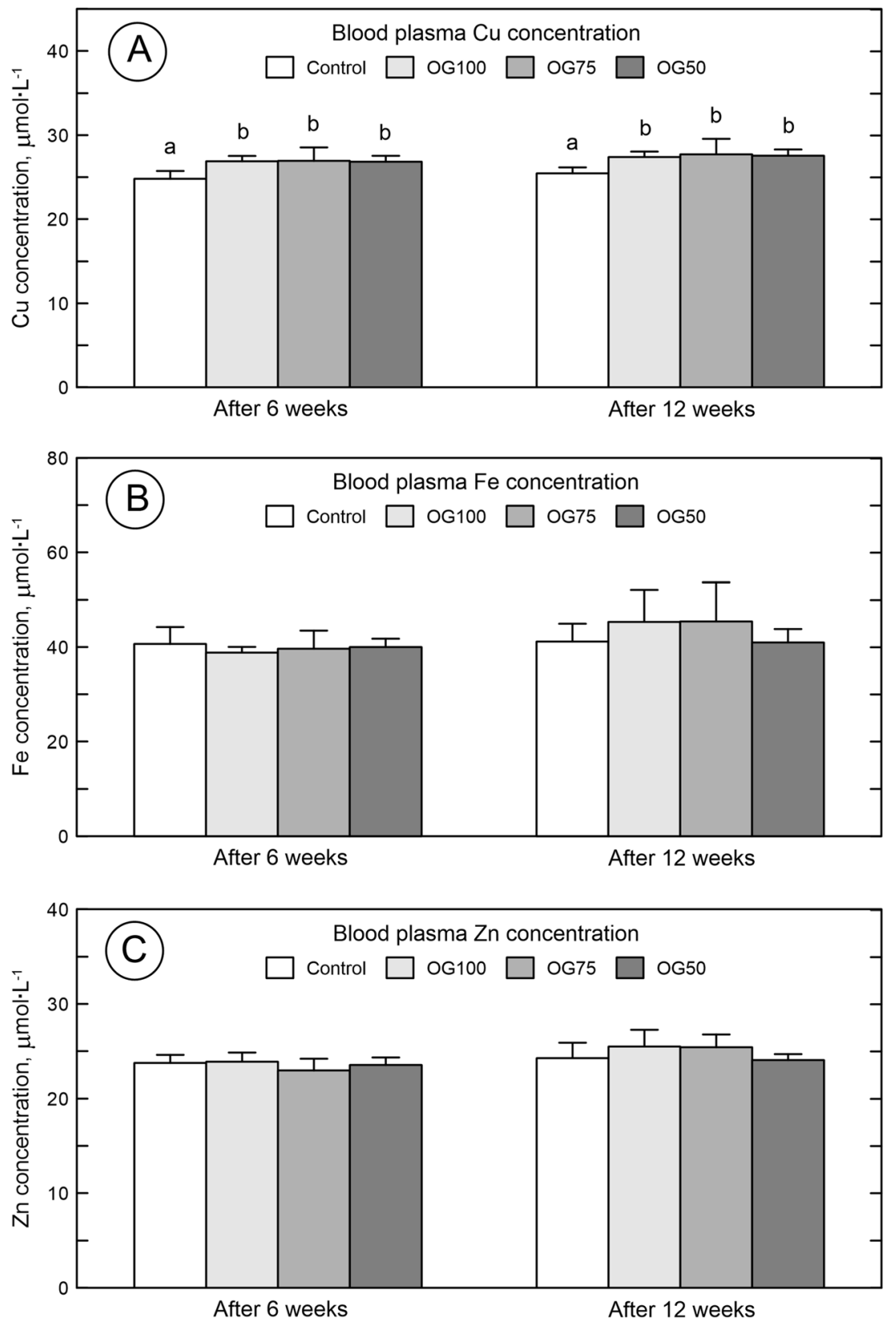

\section{Morphology of Articular and Growth Plate Cartilages}

The Cu-Gly-treatment (regardless of its concentration) significantly decreased the total thickness of the articular cartilage and increased the thickness of zone II, compared to the control group supplemented with $\mathrm{S}-\mathrm{Cu}$ (Fig. 3A). On the other hand, the influence of Cu-Gly on the thickness of zone I, III, and IV was concentration dependent. The decrease in zone I and the increase in zone III were noted in the OG100 and OG75 groups, compared to the other groups, while the thickness of zone IV decreased in the OG100 group, compared to the S$\mathrm{Cu}$-treated group and increased compared to the other $\mathrm{Cu}-$ Gly-treated groups (Fig. 3A).
The Cu-Gly-treatment in the OG75 group significantly increased the total thickness of the growth plate compared to other groups (Fig. 3B). The Cu-Gly-treatment in OG100 and OG50 groups significantly increased the thickness of zone I in the growth plate compared to the other groups. Moreover, the $\mathrm{Cu}$-Gly-treatment in OG75 and OG50 groups significantly increased the thickness of zones II and III in the growth plate compared to the other groups. On the other hand, $\mathrm{Cu}-\mathrm{Gly}$ in the OG100 decreased the thickness of zone II and IV compared to the other groups. The thickness of the zone IV decreased in the group OG75 compared to the group $\mathrm{S}-\mathrm{Cu}$ treated (Fig. 3B). 


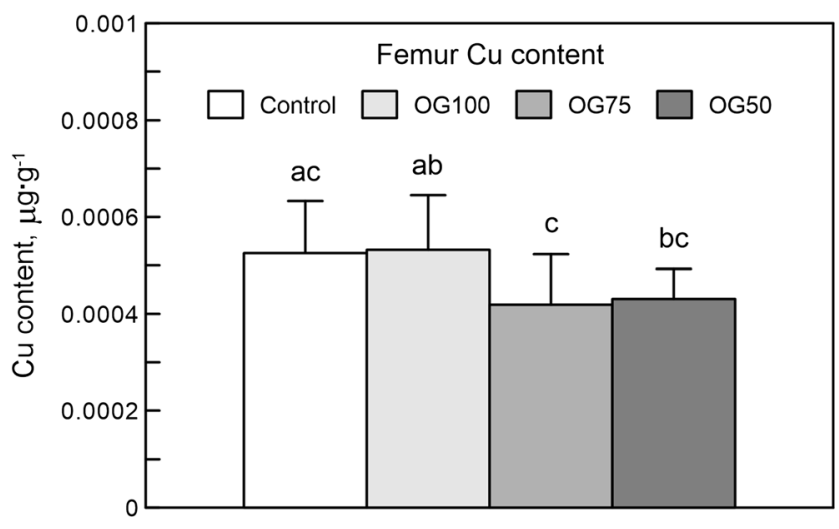

Fig. 2 The bone content of copper $(\mathrm{Cu})$ in 24-week-old rats treated with $\mathrm{Cu}$ in organic $(\mathrm{Cu}-\mathrm{Gly})$ and inorganic form $(\mathrm{S}-\mathrm{Cu})$ after 12 weeks of the duration of the study. Data given are mean $\pm \mathrm{SD}, * P<0.05$. Differences between letters given above columns $(\mathbf{a}, \mathbf{b}, \mathbf{c})$ mean significant differences with $\mathrm{P}<0.05$. The description of the groups as in the Fig. 1

\section{Proteoglycan Content in Articular Cartilages}

Proteoglycan staining with SO showed a lower proteoglycan content (exhibiting very weak red staining) in the cartilage from the OG50 group, while the other rats treated with $\mathrm{Cu}$ Gly demonstrated moderate to very strong red staining linked with a high content of proteoglycans. The concentration of proteoglycans exhibited a gradual increase with the distance from the periphery of the cartilage and loss of SO staining in the control rats supplemented with S-Cu (Fig. 4).

\section{Discussion}

It is known that correct $\mathrm{Cu}$ status in living organisms is required for proper growth [19]. A variety of indicators were used to establish the recommended levels for $\mathrm{Cu}$, including plasma $\mathrm{Cu}$ concentration, serum ceruloplasmin activity, superoxide dismutase activity, or platelet $\mathrm{Cu}$ concentration [7]. However, plasma $\mathrm{Cu}$ or ceruloplasmin is a relatively insensitive indicator [20-22]. Our earlier study shows that the $\mathrm{Cu}$ liver content (which could be a better indicator of $\mathrm{Cu}$ status) is not affected by $\mathrm{Cu}$-deficient diet (Cu-Gly) in adolescent rats [23]. Considering the role of dietary $\mathrm{Cu}$ in potentially deficient status, our rats had increased plasma $\mathrm{Cu}$ concentrations after

Table 3 Physical, mechanical, and geometric properties of the femur obtained from 24-week-old rats

\begin{tabular}{|c|c|c|c|c|c|c|}
\hline \multirow[t]{2}{*}{ Item } & \multicolumn{4}{|l|}{ Group } & \multirow[t]{2}{*}{ SEM } & \multirow[t]{2}{*}{$P$ value } \\
\hline & $\begin{array}{l}\text { CONT } \\
(n=12)\end{array}$ & $\begin{array}{l}\text { OG100 } \\
(n=12)\end{array}$ & $\begin{array}{l}\text { OG75 } \\
(n=12)\end{array}$ & $\begin{array}{l}\text { OG50 } \\
(n=12)\end{array}$ & & \\
\hline \multicolumn{7}{|l|}{ Bone general properties } \\
\hline Bone mass (g) & $1.22 \pm 0.32$ & $1.21 \pm 0.07$ & $1.27 \pm 0.16$ & $1.25 \pm 0.01$ & 0.027 & 0.825 \\
\hline Bone length (mm) & $38.20 \pm 3.66$ & $39.50 \pm 0.53$ & $39.0 \pm 1.05$ & $38.45 \pm 0.52$ & 0.298 & 0.438 \\
\hline Mass/length ratio & $0.031 \pm 0.006$ & $0.032 \pm 0.002$ & $0.032 \pm 0.003$ & $0.032 \pm 0.001$ & 0.001 & 0.489 \\
\hline \multicolumn{7}{|l|}{ Bone geometrical properties } \\
\hline Horizontal internal diameter $(\mathrm{h})(\mathrm{mm})$ & $2.72^{\mathrm{a}} \pm 0.300$ & $2.15^{\mathrm{b}} \pm 0.36$ & $2.24^{\mathrm{b}} \pm 0.06$ & $2.31^{\mathrm{b}} \pm 0.09$ & 0.049 & $<0.001$ \\
\hline Horizontal external diameter $(\mathrm{H})(\mathrm{mm})$ & $4.89^{\mathrm{a}} \pm 0.32$ & $4.33^{\mathrm{b}} \pm 0.23$ & $4.61^{\mathrm{a}, \mathrm{b}} \pm 0.32$ & $4.71^{\mathrm{a}} \pm 0.21$ & 0.052 & $<0.001$ \\
\hline Vertical internal diameter (b) (mm) & $1.93^{\mathrm{a}} \pm 0.25$ & $1.57^{\mathrm{b}} \pm 0.06$ & $1.88^{\mathrm{a}} \pm 0.08$ & $1.71^{\mathrm{b}} \pm 0.07$ & 0.030 & $<0.001$ \\
\hline Vertical external diameter (B) (mm) & $3.53^{\mathrm{a}} \pm 0.25$ & $3.18^{\mathrm{b}} \pm 0.08$ & $3.40^{\mathrm{a}} \pm 0.19$ & $3.49^{\mathrm{a}} \pm 0.112$ & 0.034 & $<0.001$ \\
\hline Cross-section area (A) $\left(\mathrm{mm}^{2}\right)$ & $9.38^{\mathrm{a}} \pm 1.51$ & $8.15^{\mathrm{a}} \pm 0.37$ & $9.45^{\mathrm{a}} \pm 1.73$ & $11.56^{\mathrm{b}} \pm 1.30$ & 0.281 & $<0.001$ \\
\hline Mean relative wall thickness (MRWT) & $0.81^{\mathrm{a}} \pm 0.24$ & $1.03^{\mathrm{b}, \mathrm{c}} \pm 0.12$ & $0.98^{\mathrm{a}, \mathrm{b}} \pm 0.15$ & $1.20^{\mathrm{c}} \pm 0.10$ & 0.033 & $<0.001$ \\
\hline Cortical index $(\mathrm{CI})(\%)$ & $43.62^{\mathrm{a}} \pm 6.96$ & $50.45^{\mathrm{b}} \pm 3.11$ & $49.30^{\mathrm{b}} \pm 4.00$ & $53.73^{\mathrm{b}} \pm 1.46$ & 0.869 & $<0.001$ \\
\hline Midshaft volume & $1.44 \pm 0.29$ & $1.29 \pm 0.04$ & $1.47 \pm 0.28$ & $1.51 \pm 0.14$ & 0.034 & 0.128 \\
\hline Moment of inertia (Ix) & $9.50^{\mathrm{a}} \pm 2.31$ & $6.55^{\mathrm{b}} \pm 0.79$ & $9.20^{\mathrm{a}} \pm 2.42$ & $9.94^{\mathrm{a}} \pm 0.99$ & 0.338 & $<0.001$ \\
\hline Index of gyration (Rg) & $1.00^{\mathrm{a}} \pm 0.05$ & $0.89^{\mathrm{b}} \pm 0.03$ & $0.98^{\mathrm{a}} \pm 0.04$ & $0.93^{\mathrm{b}} \pm 0.01$ & 0.008 & $<0.001$ \\
\hline \multicolumn{7}{|l|}{ Bone mechanical properties } \\
\hline Ultimate strength $(\mathrm{N})$ & $143.6^{\mathrm{a}} \pm 25.6$ & $177.0^{\mathrm{b}} \pm 1.0$ & $202.0^{\mathrm{c}} \pm 33.7$ & $147.8^{\mathrm{a}} \pm 13.6$ & 4.749 & $<0.001$ \\
\hline Max. elastic strength $(\mathrm{N})$ & $80.0^{\mathrm{a}} \pm 14.5$ & $125.0^{\mathrm{b}} \pm 5.3$ & $155.0^{\mathrm{c}} \pm 15.8$ & $79.1^{\mathrm{a}} \pm 10.4$ & 5.379 & $<0.001$ \\
\hline Sigma elastic & $60.8^{\mathrm{a}} \pm 19.9$ & $121.9^{\mathrm{b}} \pm 18.4$ & $118.7^{\mathrm{b}} \pm 13.3$ & $54.8^{\mathrm{a}} \pm 13.9$ & 5.555 & $<0.001$ \\
\hline Sigma max & $106.9^{\mathrm{a}} \pm 25.6$ & $172.1^{\mathrm{b}} \pm 19.8$ & $152.8^{\mathrm{b}} \pm 8.7$ & $101.9^{\mathrm{a}} \pm 22.0$ & 5.607 & $<0.001$ \\
\hline Bending moment & $3.04^{\mathrm{a}} \pm 0.61$ & $4.94^{b} \pm 0.27$ & $6.06^{\mathrm{c}} \pm 0.78$ & $3.05^{\mathrm{a}} \pm 0.44$ & 0.219 & $<0.001$ \\
\hline
\end{tabular}

Data given are mean $\pm \mathrm{SD}$. CONT - the control group received $\mathrm{Cu}$ in $100 \%$ of daily demand from sulfate $(\mathrm{S}-\mathrm{Cu}), \mathrm{OG} 100$ - the group received $\mathrm{Cu}$ in $100 \%$ of daily demand from Cu-Gly, OG75 - the group received $\mathrm{Cu}$ in $75 \%$ of daily demand from $\mathrm{Cu}-\mathrm{Gly}$, OG50 - the group received $\mathrm{Cu}$ in $50 \%$ of daily demand from $\mathrm{Cu}-\mathrm{Gly}$

a,b, c Mean values in rows with different letters differ significantly at $P<0.05$ 
Table 4 Histomorphometrical parameters of trabeculea of cancellous bone in the femur obtained from 24-week-old rats

\begin{tabular}{|c|c|c|c|c|c|c|}
\hline \multirow[t]{2}{*}{ Item } & \multicolumn{4}{|l|}{ Group } & \multirow[t]{2}{*}{ SEM } & \multirow[t]{2}{*}{$P$ value } \\
\hline & $\begin{array}{l}\text { CONT } \\
(n=12)\end{array}$ & $\begin{array}{l}\text { OG100 } \\
(n=12)\end{array}$ & $\begin{array}{l}\text { OG75 } \\
(n=12)\end{array}$ & $\begin{array}{l}\text { OG50 } \\
(n=12)\end{array}$ & & \\
\hline \multicolumn{7}{|l|}{ Femur epiphysis } \\
\hline $\mathrm{BV} / \mathrm{TV}(\%)$ & $32.08^{\mathrm{a}} \pm 2.04$ & $50.06^{\mathrm{b}} \pm 9.89$ & $50.04^{\mathrm{b}} \pm 3.89$ & $53.06^{\mathrm{b}} \pm 7.02$ & 1.629 & $<0.001$ \\
\hline Tb.Th. mean $(\mu \mathrm{m})$ & $39.81^{\mathrm{a}} \pm 3.68$ & $39.96^{\mathrm{a}} \pm 12.75$ & $40.28^{\mathrm{a}} \pm 3.89$ & $54.97^{\mathrm{b}} \pm 10.84$ & 1.692 & $<0.001$ \\
\hline Tb.Th. $\max (\mu \mathrm{m})$ & $126.2 \pm 7.8$ & $116.4 \pm 29.5$ & $118.8 \pm 44.9$ & $150.2 \pm 36.3$ & 5.371 & 0.085 \\
\hline Tb.Sp. mean $(\mu \mathrm{m})$ & $170.0^{\mathrm{a}} \pm 14.0$ & $84.1^{\mathrm{c}} \pm 6.72$ & $102.1^{\mathrm{c}, \mathrm{b}} \pm 19.1$ & $104.2^{b} \pm 18.8$ & 5.615 & $<0.001$ \\
\hline Tb.Sp. $\max (\mu \mathrm{m})$ & $373.6^{\mathrm{a}} \pm 1090.1$ & $231.03^{\mathrm{b}} \pm 31.0$ & $318.9^{\mathrm{a}, \mathrm{b}} \pm 83.6$ & $247.6^{b} \pm 68.6$ & 14.788 & $<0.001$ \\
\hline \multicolumn{7}{|l|}{ Femur metaphysis } \\
\hline $\mathrm{BV} / \mathrm{TV}(\%)$ & $36.48^{\mathrm{b}} \pm 2.30$ & $30.11^{\mathrm{a}} \pm 4.13$ & $39.22^{b} \pm 3.63$ & $33.88^{\mathrm{a}} \pm 1.73$ & 0.766 & $<0.001$ \\
\hline Tb.Th. mean $(\mu \mathrm{m})$ & $63.48^{\mathrm{a}} \pm 3.81$ & $49.16^{\mathrm{b}} \pm 10.01$ & $52.18^{\mathrm{b}} \pm 2.58$ & $51.30^{\mathrm{b}} \pm 7.69$ & 1.337 & $<0.001$ \\
\hline Tb.Th. $\max (\mu \mathrm{m})$ & $158.4^{\mathrm{a}} \pm 7.5$ & $139.2^{\mathrm{a}, \mathrm{b}} \pm 35.3$ & $115.4^{\mathrm{b}} \pm 9.8$ & $117.5^{b} \pm 20.4$ & 4.227 & $<0.001$ \\
\hline Tb.Sp. mean $(\mu \mathrm{m})$ & $153.1^{\mathrm{a}} \pm 11.9$ & $276.5^{\mathrm{c}} \pm 32.6$ & $175.7^{\mathrm{a}} \pm 13.2$ & $245.1^{\mathrm{b}} \pm 12.9$ & 8.391 & $<0.001$ \\
\hline Tb.Sp. $\max (\mu \mathrm{m})$ & $304.8^{\mathrm{a}} \pm 61.6$ & $500.3^{c} \pm 98.3$ & $308.7^{\mathrm{a}} \pm 38.8$ & $384.4^{\mathrm{b}} \pm 17.4$ & 15.403 & $<0.001$ \\
\hline
\end{tabular}

Data given are mean $\pm \mathrm{SD}$. CONT — the control group received $\mathrm{Cu}$ in $100 \%$ of daily demand from sulfate $(\mathrm{S}-\mathrm{Cu})$, OG100 - the group received $\mathrm{Cu}$ in $100 \%$ of daily demand from $\mathrm{Cu}-\mathrm{Gly}, \mathrm{OG} 75$ - the group received $\mathrm{Cu}$ in $75 \%$ of daily demand from Cu-Gly, OG50 - the group received $\mathrm{Cu}$ in $50 \%$ of daily demand from $\mathrm{Cu}-\mathrm{Gly}$

${ }^{\mathrm{a}, \mathrm{b}, \mathrm{c}}$ Mean values in rows with different letters differ significantly at $P<0.05$
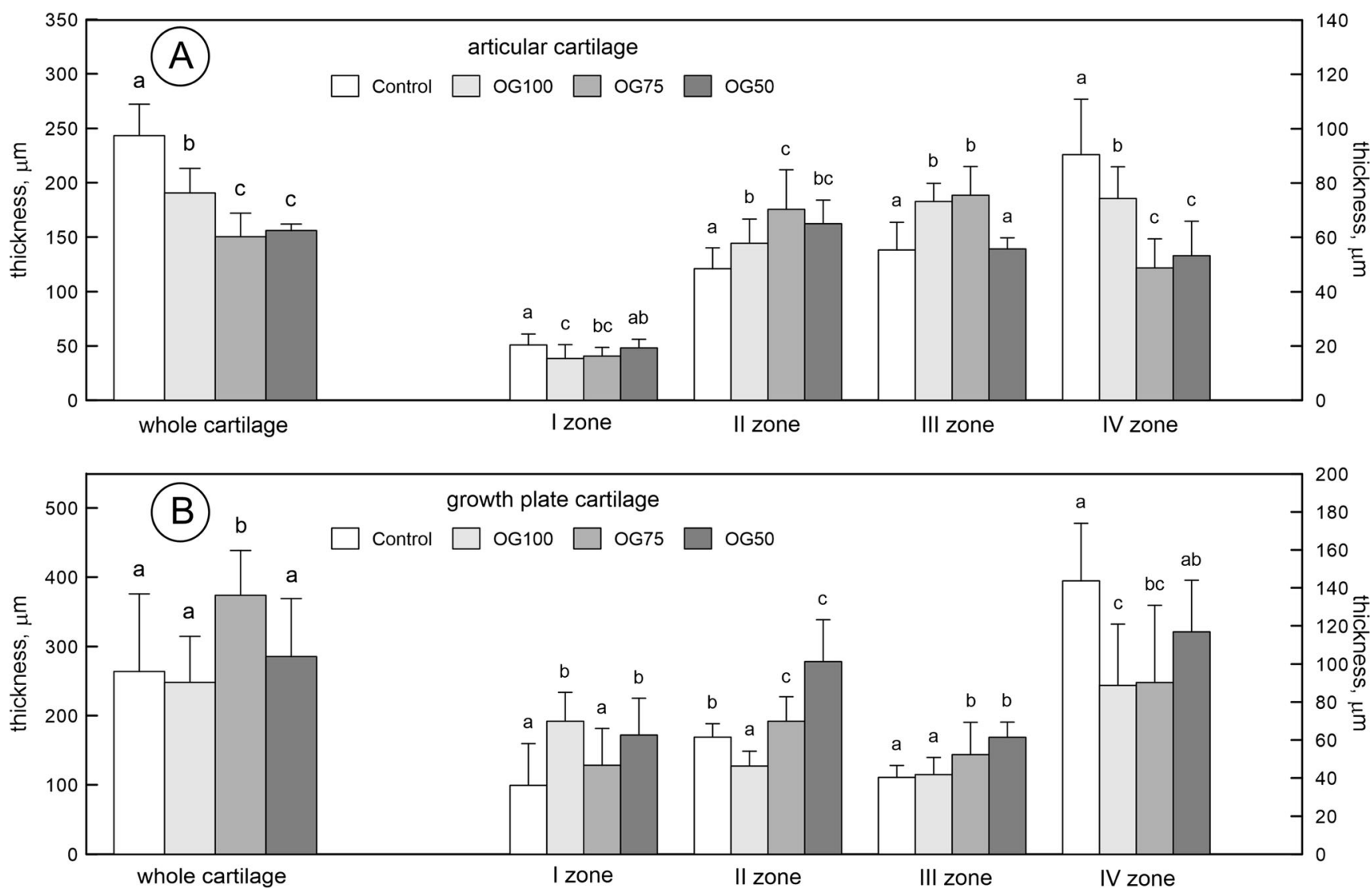

Fig. 3 The morphology of articular cartilage (A) and growth plate (B) of the femur obtained from 24-week-old rats treated with $\mathrm{Cu}$ in organic $(\mathrm{Cu}-\mathrm{Gly})$ and inorganic form $(\mathrm{S}-\mathrm{Cu})$ after 12 weeks of the duration of the study. The description of the groups as in the Fig. 1 


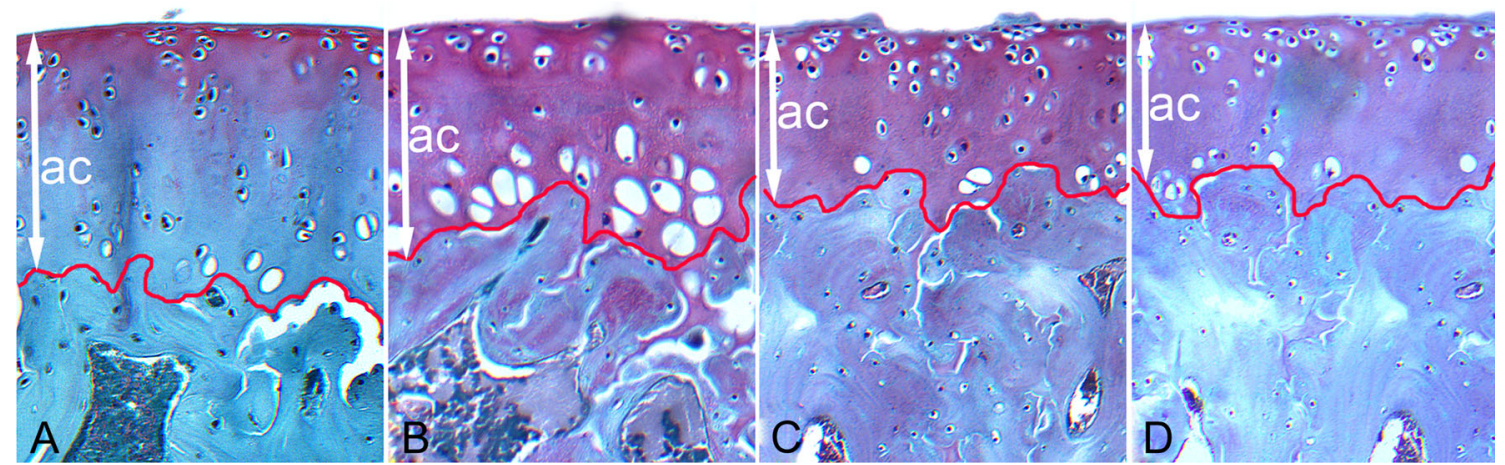

Fig. 4 Representative images of safranin-O staining carried out on formaldehyde-fixed sections from the femoral articular cartilage of 24week-old rats treated with $\mathrm{Cu}$ in organic (Cu-Gly) and inorganic form (S$\mathrm{Cu}$ ) after 12 weeks of the duration of the study. a The control group (S$\mathrm{Cu}$ ). b $100 \% \mathrm{Cu}-\mathrm{Gly}$. c $75 \% \mathrm{Cu}-\mathrm{Gly}$. d $50 \% \mathrm{Cu}-\mathrm{Gly}$. The cartilage from the OG50 group displayed a lower proteoglycan content (exhibiting very weak red staining), while the other rats treated with $\mathrm{Cu}$-Gly demonstrated

the $\mathrm{Cu}$-Gly supplementation, irrespective of the dose used. Additionally, the Fe and $\mathrm{Zn}$ concentration was not affected either. This was in agreement with another study, where $\mathrm{Zn}$ and Fe absorption and retention were generally not affected by the $\mathrm{Cu}$ addition or its sources [24]. Further, in view of the role of dietary $\mathrm{Cu}$ in general growth, our rats were characterized by the same water and feed intake. However, the Cu-Glytreatment increased the body weight of all our rats, irrespective of the $\mathrm{Cu}-\mathrm{Gly}$ concentration after 6 weeks of administration, but after 12 weeks, the positive effect on final body weight was only noted in the rats supplemented with $75 \%$ of daily demand of $\mathrm{Cu}$, compared to the control rats treated with a full dose of $\mathrm{S}-\mathrm{Cu}$. A comparison of these findings with those from other studies is somewhat difficult because no studies of the effects of $\mathrm{Cu}$-Gly supplementation at different concentrations below the daily demand are available. In agreement with our data, there is a recent study indicating that an organic form of $\mathrm{Cu}(\mathrm{Cu}$ citrate) stimulates growth at a lower concentration than that of $\mathrm{S}-\mathrm{Cu}$ in broiler and swine [22, 25]. Different results were obtained in a study with $\mathrm{Cu}$-deficient chickens, which showed no difference in body weight. Additionally, there was no difference in the basal morphology of the tibia between $\mathrm{Cu}$-deficient and control chickens [26]. There is also one study performed with $\mathrm{Cu}$-Gly added to growing chicken feed mixtures through 6 weeks, covering 100, 50, and $25 \%$ of the total requirement of the $\mathrm{Cu}$ recommended for broiler chickens, which shows that the reduction of $\mathrm{Cu}-\mathrm{Gly}$ in feed additive to $25 \%$ results in an increase in bone weight but without changes in the length [8].

In our study, there were no changes in bone morphology, but significant alteration was noted in the geometry, which was $\mathrm{Cu}$-Gly-dose dependent. Our rats supplemented with $50 \% \mathrm{Cu}-\mathrm{Gly}$ in the feed additive had less mature bone with a thicker wall. However, it did not influence its mechanical endurance. In the case of the supplementation of $75 \% \mathrm{Cu}-\mathrm{Gly}$ moderate to very strong red staining linked with a high content of proteoglycans. The concentration of proteoglycans exhibited a gradual increase with the distance from the periphery of the cartilage and loss of SO staining in the control rats supplemented with $\mathrm{S}-\mathrm{Cu}$. The description of the groups as in the Fig. 1. Red lines indicate the bottom border of articular cartilage whereas white arrow indicated its thickness. Magnification $\times 200$

in the diet, it should be considered if the reduction of one internal diameter may have resulted in the increase of the ultimate and maximal elastic strengths by 14 and 24\%, respectively, compared to the $100 \% \mathrm{Cu}$-Gly supplementation and by 41 and $93 \%$, respectively, compared to the $\mathrm{S}-\mathrm{Cu}$ group. This was the strongest effect noted among the Cu-Glysupplemented groups. Although the $100 \% \mathrm{Cu}-\mathrm{Gly}$ administration induced the greatest changes in bone geometry, the alteration in mechanical endurance was manifested less clearly (23\% increase in the ultimate force). In general, it may be proved that the supplementation of $\mathrm{Cu}$-Gly even in deficient amounts, compared to the recommended dose, can positively influence the process of bone mineralization or there is an additional mechanism, which should be studied.

Thus, it has been shown that $\mathrm{Cu}$ is required not only for proper growth but also for bone strength [19, 27]. Mature bone consists of the bone matrix (an organic phase, which includes collagen type I and noncollagenous proteins) and the mineral phase (hydroxyapatite). The amounts of these various components vary with age, gender, disease, and treatment. It was shown that although the ash weight and the calcium content of the femora from $\mathrm{Cu}$-deficient animals did not differ from those of the controls, mechanical endurance was reduced [28]. There was no effect of $\mathrm{Cu}$, even at an increased intake above the usual dietary intake, on osteocalcin (biomarker of bone metabolism) in healthy young adult females in an over 4-week period [29]. It is likely, therefore, that the impaired mechanical strength was related to defects in the collagen component of the bone [28]. Copper deficiency in man and in animals is associated with bone fragility ascribed to defective cross-links. Collagen cross-links are essential for bone to possess a sufficient deflection capacity, bending strength, and stiffness [30]. As has been mentioned, $\mathrm{Cu}$ plays a role in collagen cross-links, i.e., elements of the extracellular matrix. It has been well described that the connective tissue strength is based on 
cross-links as well as the orientation, density, and length of both collagen fibrils and fibers, and there is a functional link between the skeletal muscle cell and the bone. It is known that the force transmission of the muscle-tendon complex on bone is dependent on the structural integrity between muscle fibers and the extracellular matrix [31]. Other possible mechanisms refer to the role of $\mathrm{Cu}$ as an angiogenic factor. Poor vascularization of the cartilage is the characteristic of the lesion [32].

It should be investigated further how our Cu-Gly supplementation in the $\mathrm{Cu}$-deficient diet enhanced mechanical endurance and simultaneously triggered an osteoporotic effect in cancellous bone, especially in the femoral metaphysis. Moreover, it should be answered why the strongest osteoporotic effect in cancellous bone was observed in the group supplemented with $\mathrm{Cu}-\mathrm{Gly}$ in the recommended daily dose. Although there was no significant effect on final body weight, these rats had longer femora than the other animals; however, this was not statistically proven. Could any role be played by the bone $\mathrm{Cu}$ content, which was higher in our rats supplemented with the recommended dose of $\mathrm{Cu}$, compared to those fed $\mathrm{Cu}$-low diet? Moreover, it is interesting in which form copper is retained in the bone. It is a well-known fact that small amounts of certain metal ions can displace calcium from hydroxyapatite. On the other hand, $\mathrm{Cu}$ may also be retained by the organic part of the bone. This should be further investigated. However, it has been proven that $\mathrm{Cu}$ content in the bone is negatively correlated with bone $\mathrm{Ca}$, bone density, and collagen content in mice, and the bone $\mathrm{Cu}$ level in human subjects with osteoporosis is the same or slightly higher than in healthy individuals of the same age [33].

Our study also presented the results of the measurement of the growth plate, which indicated that the Cu-Gly complex (depending on the dose) influenced the growth plate in a different manner. The complex Cu-Gly given in $100 \%$ of demand reduced the proliferative zone, which may indicate disturbances in the cell cycle, division, and differentiation accompanied by a decrease in the rate of chondrocyte proliferation, as well as the thickness of bone trabeculae, which became thinner with the highest separation. $\mathrm{Cu}$ supplementation in the dose of $75 \%$ of demand increased the total thickness and hypertrophy zone; this may suggest a reduced degree of mineralization (reduced zone IV), which depends on the size and number of cells in the hypertrophic zone of the growth plate and the amount of calcium released from the mitochondrion. The dose of $50 \%$ of demand caused disturbances in bone growth and influenced its geometry, not only the architecture of the trabeculae. The present study also showed a significant decrease in the articular cartilage thickness in the rats supplemented with $\mathrm{Cu}-\mathrm{Gly}$, irrespective of its dose. The shortening of the superficial zone in our rats can change the distribution of the load through the joint with functional consequences. It might trigger the degradation of the articular cartilage, thereby causing difficulties in movement, because the reduction of this zone can change the elasticity of articular cartilage, which contributes to reversibility of the deformation caused by the impact of the load during movement. Thus, the organic form may lead to alterations within the cartilage during normal function and, with time, osteoarthritis can develop. On the other hand, the supplementation of $\mathrm{Cu}$-Gly seemed to enhance the proteoglycan content in articular cartilage (Fig. 4). The degradation of proteoglycans can play a pivotal role in destabilization of the collagen network. Proteoglycans ensure stability of articular cartilage and their content in normal cartilage is directly proportional to the intensity of safranin-O staining, which has been used to demonstrate any changes that occur in articular diseases [34].

However, the level of the chemical $\mathrm{Cu}$ form applied in these observations is important, because the reference group was given $\mathrm{Cu}$ at the same dose but in the S-Cu form. Copper, when fed at prophylactic concentrations, may function by increasing absorption or by providing growth-promoting effects, possibly by shifting the microbial populations within the gastrointestinal tract [35] or through other unknown mechanisms. Because different $\mathrm{Cu}$ sources have different relative bioavailabilities [35], the mechanism and extent of growth-promoting effects are rather varied. Attempts to quantify the bioavailability when fed at marginally deficient concentrations of alternate sources of $\mathrm{Cu}$ are numerous. For those particular studies, copper sulfate (S$\mathrm{Cu}$ ) has been used as a reference point for comparing the relative bioavailability of various $\mathrm{Cu}$ sources [35].

To the best of our knowledge, this is the first study that has examined both the mechanical properties of the bone and histomorphometry of the trabecular bone and hyaline cartilage not only in $\mathrm{Cu}$-deficient diet but also in diet with a similar level of $\mathrm{Cu}$ given in a different source.

\section{Conclusions}

No studies conducted so far have provided a detailed morphological analysis of the growth plate, cancellous bone, and articular cartilage of adult rats administered with diet containing different $\mathrm{Cu}$ forms. Moreover, the $\mathrm{Cu}$-Gly treatment influenced the trabecular architecture and morphology of the growth plate in dose-dependent manner. However, dietary $\mathrm{Cu}$ given to adult rats in the $\mathrm{Cu}$-Gly complex covering the daily demand in $75 \%$ exerted a positive effect on bone metabolism and appeared to be the most effective among the investigated doses of the organic form.

\section{Compliance with Ethical Standards}

Conflict of Interest The authors declare that they have no conflict of interest.

Funding This study was funded by grants of Ministry of Science and Higher Education: WKF/DS-1 to ET, and BS-01-1200-0000 to PD. 
Open Access This article is distributed under the terms of the Creative Commons Attribution 4.0 International License (http:// creativecommons.org/licenses/by/4.0/), which permits unrestricted use, distribution, and reproduction in any medium, provided you give appropriate credit to the original author(s) and the source, provide a link to the Creative Commons license, and indicate if changes were made.

\section{References}

1. Peňa MM, Lee J, Thiele DJ (1999) A delicate balance: homeostatic control of copper uptake and distribution. J Nutr 1129:1251-1260

2. Rinaldi AC (2000) Meeting report-copper research at the top. Biometals 13:9-13

3. Lanocha N, Kalisinska E, Kosik-Bogacka DI, Budis H, Sokolowski S, Bohatyrewicz A (2013) Comparison of metal concentrations in bones of long-living mammals. Biol Trace Elem Res 152:195-203. doi:10.1007/s12011-013-9615-x

4. Rodríguez JP, Ríos S, González M (2002) Modulation of the proliferation and differentiation of human mesenchymal stem cells by copper. J Cel Biochem 85:92-100

5. Linder MC, Hazegh-Azam M (1996) Copper biochemistry and molecular biology. Am J Clin Nutr 63:797-811

6. Nielsen FH, Milne DB (2004) A moderately high intake compared to a low intake of zinc depresses magnesium balance and alters indices of bone turnover in postmenopausal women. Eur J Clin Nutr 58:703-710. doi:10.1038/sj.ejcn.1601867

7. Palacios C (2006) The role of nutrients in bone health, from $A$ to $Z$. Crit Rev Food Sci Nutr 46:621-628

8. Kwiecień M, Winiarska-Mieczan A, Zawiślak K, Sroka S (2014) Effect of copper glycinate chelate on biomechanical, morphometric and chemical properties of chicken femur. Ann Anim Sci 14:127-139

9. Megahed MA, Hassanin KMA, Youssef IMI, Elfghi ABA, Amin KA (2014) Alterations in plasma lipids, glutathione and homocysteine in relation to dietary copper in rats. J Invest Biochem 3:21-25. doi:10.5455/jib.20130716075753

10. Ferretti JL, Capozza RF, Mondelo N, Zanchetta JR (1993) Interrelationships between densitometric, geometric and mechanical properties of rat fem ora: inferences concerning mechanical regulation of bone modelling. J Bone Miner Res 8:1395-1399

11. Tomaszewska E, Dobrowolski P, Bieńko M, Prost $€$, Szymańczyk S, Zdybel A (2015) Effects of 2-oxoglutaric acid on bone morphometry, densitometry, mechanics, and immunohistochemistry in 9-month-old boars with prenatal dexamethasone-induced osteopenia. Connect Tissue Res 56:483-492. doi:10.3109/03008207.2015.1069822

12. Tomaszewska E, Dobrowolski P, Winiarska-Mieczan A, Kwiecień M, Tomczyk A, Muszyński S, Radzki R (2016) Alteration in bone geometric and mechanical properties, histomorphometrical parameters of trabecular bone, articular cartilage and growth plate in adolescent rats after chronic co-exposure to cadmium and lead in the case of supplementation with green, black, red and white tea. Environ Toxicol Pharmacol 46:36-44. doi:10.1016/j. etap.2016.06.027

13. Dobrowolski P, Tomaszewska E, Kurlak P, Pierzynowski SG (2016) Dietary 2-oxoglutarate mitigates gastrectomy-evoked structural changes in cartilage of female rats. Exp Biol Med (Maywood) 241:14-24. doi:10.1177/1535370215595466

14. Tomaszewska E, Dobrowolski P, Wydrych J (2012) Postnatal administration of 2-oxoglutaric acid improves articular and growth plate cartilages and bone tissue morphology in pigs prenatally treated with dexamethasone. J Physiol Pharmacol 63:547-554

15. Suvara SK, Layton C, Bancroft JD (2012) Bancroft's theory and practice of histological techniques, 7 th edition., Churchill Livingstone Elsevier
16. Hochberg Z (2002) Clinical physiology and pathology of the growth plate. Best Pract Res Clin Endocrinol Metab 16:399-419

17. Tomaszewska E, Dobrowolski P, Puzio I (2013) Morphological changes of the cartilage and bone in newborn piglets evoked by experimentally induced glucocorticoid excess during pregnancy. J Anim Physiol Anim Nutr (Berl) 97:785-796

18. AOAC (2000) Official methods of analysis, Int. 17th edn. AOAC Inter, Gaithersburg, MD, USA

19. Uauy R, Olivares M, Gonzalez M (1998) Essentiality of copper in humans. Am J Clin Nutr 67:952S-959S

20. Milne DB, Nielsen FH (1996) Effects of a diet low in copper on copper-status indicators in postmenopausal women. Am J Clin Nutr 63:358-364

21. Baker A, Harvey L, Majsak-Newman G, Fairweather-Tait S, Flynn A, Cashman K (1998) Effect of dietary copper intakes on biochemical markers of bone metabolism in healthy adult males. Eur J Clin Nutr 53:408-412

22. Armstrong TA, Cook DR, Ward MM, Williams CM, Spears JW (2004) Effect of dietary copper source (cupric citrate and cupric sulfate) and concentration on growth performance and fecal copper excretion in weanling pigs. J Anim Sci 82:1234-1240

23. Tomaszewska E, Dobrowolski P, Kwiecień M, Burmańczuk N, Badzian B, Szymańczyk S, Kurlak P (2014) Alterations of liver histomorphology in relation to copper supplementation in inorganic and organic form in growing rats. Bull Vet Inst Pulawy 58:479-486

24. Apgar GA, Kornegay ET (1996) Mineral balance of finishing pigs fed copper sulfate or a copper-lysine complex at growth-stimulating levels. J Anim Sci 74:1594-1600

25. Pesti GM, Bakalli RI (1996) Studies on the feeding of cupric sulfate pentahydrate and cupric citrate to broiler chickens. Poult Sci 75: 1086-1091

26. Riggins RS, Catwkights AG, Ruckers RB (1979) Viscoelastic properties of copper deficient chick bone. J Biomech 12:197-203

27. Baxter JH, Van Wyk JJ (1953) A bone disorder associated with copper deficiency. I. Gross morphological, roentgenological, and chemical observations. Bull Johns Hopkins Hosp 93:1-23

28. Jonas J, Burns J, Abel EW, Cresswell MJ, Strain JJ, Paterson CR (1993) Impaired mechanical strength of bone in experimental copper deficiency. Ann Nutr Metab 37:245-252

29. Cashman KD, Baker A, Ginty F, Flynn A, Strain JJ, Bonham MP, O'Connor JM, Bügel S, Sandström B (2001) No effect of copper supplementation on biochemical markers of bone metabolism in healthy young adult females despite apparently improved copper status. Eur J Clin Nutr 55:525-531

30. Oxlund H, Barckman M, Ørtoft G, Andreassen TT (1995) Reduced concentrations of collagen cross-links are associated with reduced strength of bone. Bone 17:365S-371S

31. Kjaer M (2004) Role of extracellular matrix in adaptation of tendon and skeletal muscle to mechanical loading. Physiol Rev 84:649698. doi:10.1152/physrev.00031.2003

32. Opsahl W, Zeronian H, Ellison M, Lewis D, Rucker RB, Riggins RS (1982) Role of copper in collagen cross-linking and its influence on selected mechanical properties of chick bone and tendon. J Nutr 112:708-716

33. Beattie JH, Avenell A (1992) Trace element nutrition and bone metabolism. Nutr Res Rev 5:167-188. doi:10.1079/NRR19920013

34. Camplejohn KL, Allard SA (1988) Limitations of safranin 'O' staining in proteoglycan-depleted cartilage demonstrated with monoclonal antibodies. Histochemistry 89:185-188

35. Banks KM, Thompson KL, Rush JK, Applegate TJ (2004) Effects of copper source on phosphorus retention in broiler chicks and laying hens. Poult Sci 83:990-996 